\title{
Intervençáo Terapêutica Ocupacional junto à criança com Distrofia Muscular de Duchenne (DMD): um estudo de caso
}

\author{
Tábita Enila Campos Rocha Raboni ${ }^{\mathrm{a}}$, Milena Fazzio Marino da Silva ${ }^{\mathrm{b}}$, Luzia Iara Pfeifer ${ }^{\mathrm{c}}$ \\ ${ }^{a}$ Graduanda de Terapia Ocupacional, Faculdade de Medicina de Ribeirão Preto - FMRP, \\ Universidade de São Paulo - USP, Ribeirão Preto, SP, Brasil

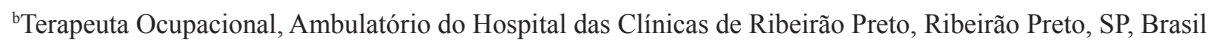 \\ 'Professora Doutora, Docente do Curso de Graduação em Terapia Ocupacional, \\ Faculdade de Medicina de Ribeirão Preto - FMRP, Universidade de São Paulo - USP, Ribeirão Preto, SP, Brasil
}

\begin{abstract}
Resumo: A distrofia muscular de Duchenne é uma doença progressiva que acomete a musculatura, levando a debilidade e fraqueza excessivas. Este estudo de caso descreve a intervenção Terapêtica Ocupacional junto a uma criança com distrofia muscular de Duchenne, visando à prevenção da inatividade funcional, causada pelo processo de agravamento progressivo, principalmente das funções locomotoras, que muitas vezes geram complicações emocionais, isolamento social, déficits cognitivos e desajuste familiar; objetivou-se, assim, um desempenho ocupacional saudável. Na avaliação inicial, a criança apresentava movimentos e posturas compensatórias, inclusive para deambulação, dificuldade para realizar mudanças posturais e coordenação motora global debilitada; porém, não havia dificuldade com coordenação motora fina, bem como com função uni e bimanual, e preensões. Quanto aos aspectos cognitivos, apresentava dificuldades de aprendizagem e dava preferência a brinquedos inadequados para a sua idade. Os principais objetivos terapêuticos tiveram como focos o desempenho das ocupações relacionadas às AVDs, o brincar, a educação e a participação. Os atendimentos foram realizados de agosto a novembro de 2007 e de maio a julho de 2009, uma vez por semana, com duração média de 45 minutos. Como a distrofia muscular de Duchenne é uma doença de caráter progressivo, algumas dificuldades, como caminhar, levantar e manter o posicionamento adequado dos pés, se intensificaram, levando à necessidade do uso de cadeira de rodas. Contudo, evidenciou-se, durante os atendimentos, que o brincar se ajustou, a participação social foi estimulada, a adequação do ambiente escolar permitiu seu desempenho nessa área, bem como a maior independência nas AVDs, melhorando sua qualidade de vida, assim como de sua família.
\end{abstract}

Palavras-chave: Terapia Ocupacional, Distrofia Muscular de Duchenne, Atendimento Ambulatorial.

\section{Occupational Therapeutic Intervention in children with Duchenne Muscular Dystrophy (DMD): a case study}

\begin{abstract}
Duchenne muscular dystrophy is a progressive disorder that affects the musculature leading to debility and excessive weakness. This study describes an occupational therapy intervention in a child suffering of Duchenne muscular dystrophy. The intervention sought to prevent the functional inactivity caused by the progressive aggravation process, mainly of the motor coordination, which sometimes causes emotional damage, social isolation, cognitive deficitand family dysfunction, thus aimingto reach a healthy occupational performance. In the initial assessment, the child presented compensatory movements and posture- including roam,difficulty to perform postural changes and poor global motor coordination, but no difficulty in fine-motor coordination as well as in uni/bimanual and prehension functions. Regarding the cognitive aspects, thechild showed learning difficulties and was interested only in toys that were inadequate for the age. The main therapeutic goals focused on the performance of occupations related to the activities of daily living (ADLs), playing, education and
\end{abstract}

Autor para correspondência: Luzia Iara Pfeifer, Departamento de Neurologia, Psiquiatria e Psicologia Médica, Faculdade de Medicina de Ribeirão Preto - FMRP, Universidade de São Paulo - USP, Av. Bandeirantes, 3900, 4 andar do HCFMRP, Monte Alegre, CEP 14049-900, Ribeirão Preto, SP, e-mail: luziara@fmrp.usp.br

Recebido em 17/11/2009; $1^{\text {a }}$ Revisão em 8/1/2010; $2^{\text {a }}$ Revisão em 16/3/2010; Aceito em 24/3/2010. 
participation. The treatment occurred from August to November 2007 and from May to July 2009, once a week, 45 minutes in average. AsDuchenne muscular dystrophyis a progressive disorder, some difficultiesin walking, standing and keeping the adequate feet positioning intensified, leading to the necessity of using a wheelchair. However,along the treatment, it was possible to notice some adjustment in the playing, motivation in social participation,adequacy to the schoolenvironment that enabled progress in this area, as well as more independence in the ADLs, improving the quality of life of the child and the child's family.

Keywords: Occupational Therapy, Duchenne Muscular Dystrophy, Outpatient Care.

\section{Introdução}

A Distrofia Muscular de Duchenne (DMD) é uma doença neuromuscular genética de caráter recessivo, ligada ao cromossomo X (ARAÚJO et al., 2004). É transmitida pela mãe em dois terços dos casos e, em um terço, por mutaçóes novas, tornando importante o aconselhamento genético. É a miopatia mais comum na infância, afetando um em cada três mil a quatro mil nascidos do gênero masculino. Sua causa é a deficiência da distrofina, uma proteína da membrana da fibra muscular responsável por manter sua integridade (ZANOTELI; BETERA, 2003).

As manifestações clínicas iniciais são debilidade e/ou fraqueza muscular da cintura pélvica (região da bacia), principalmente nos músculos extensores e abdutores do quadril, atingindo posteriormente os músculos da cintura escapular (região do ombro); tais manifestações, normalmente, aparecem em torno de 3 a 5 anos de idade (SILVA; COSTA; CRUZ, 2003). Observa-se, também, a contratura ou a retração tendínea, principalmente nas articulaçóes de quadril, joelho e tornozelos, em padróes de flexão de quadril e joelho, flexão plantar de tornozelo, limitando os movimentos de extensão de quadril, joelho e a dorsiflexão do tornozelo (SILVA; COSTA; CRUZ, 2003). O encurtamento do músculo responsável pela flexão dorsal dos pés favorece a marcha nas pontas dos pés, caracterizando a marcha anserina; com a progressão da doença, ocorre aumento da lordose lombar e o exagero desse tipo de marcha (CAROMANO, 1999).

As crianças que possuem DMD apresentam sinal característico para se levantarem, denominado Sinal de Gowers (levantamento miotático), em que realizam um rolamento para ficarem de joelhos e, com os antebraços estendidos, apoiam-se no chão, com o intuito de levantar as nádegas e os joelhos para poderem se erguer (SILVA; COSTA; CRUZ, 2003).

A fraqueza excessiva evolui para incapacidade de andar e, apesar de não haver consenso entre os estudiosos, a maioria dos autores, como Zanoteli e Beteta (2003), defendem que as crianças perdem a capacidade de deambular por volta de nove a
12 anos de idade. $\mathrm{O}$ quadro vai se agravando até o comprometimento atingir toda a musculatura esquelética e surgirem problemas cardíacos e respiratórios; estes últimos são em virtude das alterações ocorridas no músculo diafragma e não porque os pulmóes estejam afetados. A partir disso, como colocam esses autores, complicaçóes, como deformidade de coluna (principalmente escoliose) e insuficiência respiratória, conduzem a um prognóstico desfavorável. Fonseca, Machado e Ferraz (2007) estimam que 55 a $90 \%$ dos pacientes morrem por insuficência respiratória entre 16 e 19 anos, e raramente após os 25 anos. A DMD não tem cura, porém a atuação integrada de uma equipe de reabilitação - composta por Fisioterapeuta, Terapeuta Ocupacional, Fonoaudiólogo, Psicólogo, Médico, Pedagogo e Assistente Social - pode trazer grandes contribuições para controlar a progressão da doença e aumentar a qualidade de vida desses pacientes (ZANOTELI; BETETA, 2003).

A atuação da Terapia Ocupacional consiste em favorecer o papel ocupacional do indivíduo, prevenindo a inatividade funcional, causada pelo processo de agravamento progressivo, principalmente das funçóes locomotoras, que muitas vezes geram complicaçóes emocionais, isolamento social, déficits cognitivos, desajuste familiar, dentre outras. Hassui (2003) diz que cabe a esse profissional a criação de estratégias que incentivem o sujeito a continuar agindo sobre o mundo, mantendo sua capacidade criativa, expressiva e produtiva, de forma que possa conhecer, superar ou minimizar o impacto de suas limitaçóes no cotidiano e fazer surgir e transparecer suas capacidades e potencialidades.

Esse autor ressalta ainda que o foco da atenção deve ser sempre o sujeito com suas necessidades, expectativas, angústias e desejos. Pensando nisso, é importante que haja interação entre sujeito, família/ cuidadores e equipe de reabilitação, criando, juntos, estratégias de trabalho capazes de responder a essas necessidades. 
Ao Terapeuta Ocupacional caberá promover a manutenção e/ou a melhora da força muscular, da amplitude de movimento, da função manual; prevenir encurtamentos e deformidades; realizar estimulação perceptocognitiva e auxiliar no processo de conscientização e imagem corporal, fazendo perceber as mudanças ocorridas no corpo; estimular a maior independência possível nas atividades de vida diária; realizar orientação quanto ao posicionamento adequado; prescrever adaptaçôes em mobiliários e utensílios, e órteses quando necessário, e realizar orientação familiar (HASSUI, 2003).

A partir desses conhecimentos, foi desenvolvido um processo interventivo terapêutico ocupacional junto a uma criança com o diagnóstico de distrofia muscular progressiva de Duchenne.

Os atendimentos ora apresentados foram realizados no ambulatório de Terapia Ocupacional - Área de Infância e Adolescência, inserido em um hospital universitário no interior do Estado de São Paulo, no período de agosto a novembro de 2007 e de maio a julho de 2009. Esses atendimentos foram realizados por duas duplas de acadêmicos, supervisionados diretamente por uma Terapeuta Ocupacional, que trabalha no referido hospital, e supervisionados indiretamente por uma docente do curso de graduação em Terapia Ocupacional. Esses atendimentos fazem parte das atividades práticas $\mathrm{da}$ disciplina Terapia Ocupacional Aplicada às Condiçóes Clínicas da Infância e Adolescência, ministrada no sexto semestre do referido curso de graduação. Essa disciplina utiliza a metodologia problematizadora, sendo que os acadêmicos são apresentados a situaçôes problemas para que, a partir destas, seja desenvolvido o raciocínio clínico e incentivado o aprendizado de conteúdos teóricos que darão suporte à intervenção terapêutica ocupacional.

\section{Objetivos}

Este estudo tem como objetivo apresentar o processo de intervençáo terapêutica ocupacional junto a uma criança portadora de Distrofia Muscular de Duchenne.

\section{Metodologia}

\subsection{Participante}

V., nascido em 26/nov./1998, de parto normal, a termo, após uma gestação sem intercorrências, filho único de um casal, moradores de Ribeirão Preto, SP. O pai tem 32 anos e trabalha como porteiro e a mãe tem 23 anos e trabalha como empregada doméstica. Esta refere que desde que começou a andar, a criança cai muito, corre com dificuldade, tem pouca agilidade com movimentos rápidos e tem dificuldade para levantar do solo, procurando se apoiar.

Após estudo genético e densitometria óssea, foi solicitada internação para biópsia muscular em 15/ago./2005, o que confirmou o diagnóstico de DMD. A mãe relata a inexistência de antecedentes familiares. Em exame médico, realizado em 10/ maio/2007, foi observada fraqueza generalizada grau 4, acentuação da lordose lombar, báscula de quadril, andar na ponta dos pés, sinal de Gowers, pseudo- hipertrofia das panturrilhas, sem restriçōes articulares.

Começou a ser atendido pela terapia ocupacional em 08/maio/2007, sendo que pela primeira dupla de acadêmicas em 14/ago./2007 e, pela segunda dupla de acadêmicas, em 13/maio/2009. Durante todo esse processo, sempre foi mantida uma Terapeuta Ocupacional de referência, a qual era supervisora das acadêmicas e deu continuidade aos atendimentos, no intervalo entre as duplas.

\subsection{Procedimento para coleta de dados}

As informaçóes acerca do histórico clínico da criança foram colhidas no prontuário médico e durante os atendimentos, em conversas com a mãe. Inicialmente, foi realizada uma avaliação. Os procedimentos terapêuticos ocupacionais realizados junto à criança foram registrados no prontuário, logo em seguida aos atendimentos, destacando os objetivos, as atividades e as respostas das mesmas.

\subsection{Procedimentos de análise de dados}

Foram analisadas as informaçôes acerca do histórico clínico de forma a descrever e compreender as características da criança. A avaliação foi analisada a fim de traçar um panorama dos componentes de desempenho ocupacionais da criança, para se definir o plano de tratamento com os objetivos terapêuticos a serem atingidos. Os registros do prontuário foram analisados a partir das atividades utilizadas e dos objetivos atingidos junto à criança.

\section{Resultados}

\subsection{Avaliação}

Foi identificado que V. apresentava movimentos e posturas compensatórias, inclusive para deambulação, 
dificuldade para realizar mudanças posturais (em função do desenvolvimento natural da doença) e coordenação motora global debilitada, mas sem dificuldade com coordenação motora fina, bem como com função uni e bimanual e preensóes. Quanto aos aspectos cognitivos, apresentava dificuldades de aprendizagem, possivelmente em razão da dificuldade em manter atenção seletiva e concentração. Dava preferência a brinquedos inadequados para a sua idade.

A mãe relatou que a criança realiza parte das suas AVD, sendo por ela auxiliada, por causa mais do tempo que demora em realizá-las do que pela sua dificuldade. Em relação à escola, queixou-se que V. tem de ficar o tempo todo sentado, pois, como náo consegue correr como os amigos, ele acaba se machucando.

A partir desse diagnóstico ocupacional, foram traçados os seguintes objetivos terapêuticos ocupacionais: melhora das áreas de desempenho ocupacional relacionadas à participação social, ao brincar e às atividades de vida diária (AVDs), e orientação familiar.

Para atingir essas áreas de desempenho, foi necessário focalizar alguns componentes de desempenho, como: amplitude de movimento (ADM); coordenação motora global (CMG); conscientização corporal; posicionamento adequado (principalmente dos pés), prevenindo encurtamentos e deformidades; estímulo da atençáo seletiva e da concentração, e adequação de atividades de acordo com a idade e a criatividade.

\subsection{Intervenções terapêuticas ocupacionais}

Foram analisados 20 atendimentos de Terapia Ocupacional, sendo 12 atendimentos no período de agosto a novembro de 2007 e oito atendimentos de maio a julho de 2009. Esses atendimentos têm duração de aproximadamente 45 minutos cada, ocorrem semanalmente e são desenvolvidos por duas acadêmicas do sexto semestre do curso de graduação em Terapia Ocupacional, conforme descrito anteriormente. Assim, os resultados são apresentados pelas atividades desenvolvidas e não pelas sessôes de atendimento, já que muitas atividades duraram mais do que uma sessão.

Para atingir esses objetivos terapêuticos ocupacionais, foram utilizadas diversas estratégias, quais sejam:

- Atividade estruturada com comandos: no primeiro contato, traçaram-se como objetivos a aproximação e o conhecimento de V., com comandos que mostrariam suas preferências e um pouco da sua vida, como: "desenhe sua família", "escreva o nome de seu melhor amigo", "o que você mais gosta de comer", entre outros, escritos em pedaço de papel, que V. retirava de um pote. Componentes de desempenho trabalhados: atenção e interação social. Essa atividade propiciou uma maior aproximação de $\mathrm{V}$, que se mostrou bastante inibido e pouco à vontade, inicialmente;

- Montagem de um painel: atividade para alongamento da musculatura das panturrilhas e braços, e para dar continuidade à atividade anterior, favorecendo um maior contato com as acadêmicas. Com uma cartolina colada na parede, V. deveria colar os trabalhos realizados na atividade anterior. Componentes de desempenho trabalhados: alongamento da musculatura, $\mathrm{ADM}$ e posicionamento correto dos pés (utilização de cunha). V. pôde dar continuidade à atividade iniciada anteriormente e enriquecer as informaçôes sobre sua vida. Mostrou-se mais à vontade ao contato com as estagiárias e apresentou certa dificuldade ao colar os trabalhos na parede, se desequilibrando quando mantinha os braços no alto;

- Confecção e jogo de peteca de jornal: desenvolver brincadeira que estimule sua habilidade motora e equilíbrio, bem como sua criatividade. V. confeccionou uma peteca juntamente com as acadêmicas, utilizando tesoura, fita adesiva e jornal, e, após isso, brincou de jogar. Componentes de desempenho trabalhados: alongamento, ADM, CMG, equilíbrio dinâmico e atençấo. V. foi estimulado a se envolver com novas brincadeiras e habilidades. Ele ainda se apresentava resistente para se envolver em novas brincadeiras, sempre desviando sua atenção para brinquedos inadequados para a sua idade, como aqueles de ação e reação;

- Pintura (com pincel, dedo, mãos, pés, bolinhas): atividade para estimular a percepção corporal e a criatividade. A pintura foi realizada em papel pardo colado no chão. Componentes de desempenho trabalhados: $\mathrm{CMG}$, propriocepção e consciência corporal. V. pôde experimentar diferentes formas de pintar utilizando pincéis, os dedos das máos e os pés. Foi estimulado a um reconhecimento de seu corpo e de suas 
habilidades. Mostrou-se inibido em usar seu corpo inicialmente, mas logo se permitiu experimentar e utilizou muito as mãos e os pés;

- Atividade de faz-de-conta - Pirata: atividade estruturada pensando nos aspectos motores e cognitivos, estimulando a criatividade e o faz-de-conta. Foi confeccionado um chapéu de pirata com jornal, foi usado um rolo terapêutico como barco e tapetes texturizados (propriocepçáo). V. deveria acertar uns barquinhos desenhados no espelho e depois encontrar um tesouro (bombons), seguindo uma pista escrita. Componentes de desempenho trabalhados: CMG, ADM, descarga de peso e propriocepçáo, consciência corporal e faz-de-conta (criatividade). Essa atividade foi estruturada de modo a estimular sua criatividade e mostrar-lhe outras possibilidades de desenvolver algumas brincadeiras. Nessa atividade, V. apresentou-se bastante desinibido, envolveu-se facilmente nas atividades e demonstrou um faz-de-conta bastante elaborado, desenvolvendo bem a brincadeira. $\mathrm{O}$ espelho também serviu para atentá-lo sempre para a posição correta dos pés;

- Confeçãa de máscara e capa de super-herói: atividade com o objetivo de estimular e desenvolver as características potenciais de V., como a criatividade e o faz-de-conta. V. confeccionou uma máscara e uma capa de super-herói, utilizando cartolina, lápis de cor, elástico, TNT e tesoura. Posteriormente, foi estimulado a pensar nos poderes que seu super-herói teria. Componentes de desempenho trabalhados: atenção, concentração e criatividade. Interagiu bem e apresentou uma imaginação bastante desenvolvida;

- Atividade de faz-de-conta - Super-herói: possibilitar a livre expressão da criatividade e do faz-de-conta, além de alongamento da musculatura da cintura escapular. Nessa atividade, V. era um super-herói que deveria resgatar "bombas" (bolas) espalhadas pela "cidade" (sala de atendimento) em diferentes planos. Componentes de desempenho trabalhados: ADM, CMG, faz-de-conta, criatividade e propriocepção (papel da missão escondido em um dos potes com grãos). V. desenvolveu a brincadeira com muita criatividade e um faz-de-conta bastante elaborado; além disso, cumpriu a tarefa estabelecida, encontrando e resgatando todas as "bombas";

- Visita Domiciliar: foi realizada uma visita domiciliar para a observação de atividades de vida diária (alimentação, vestuário, higiene), da dinâmica familiar, do imóvel e do mobiliário, para possíveis sugestôes de adaptaçōes futuras. Foi observado que V. possui órteses (confeccionadas pelo fisioterapeuta) para a posiçáo correta dos pés, para uso noturno, mas a mãe relatou que a criança não se adaptou e, portanto, não a utiliza. A mãe o ajuda em partes das atividades de autocuidado, como colocar vestuário e tomar banho. Ela foi orientada a promover o máximo possível da independência de V. nas AVDs e alertada sobre a importância do posicionamento adequado dos pés e das costas quando $V$. estiver sentado (adaptação de um banquinho para o apoio dos pés), comendo ou jogando vídeo game. Outra adaptação possível seria de uma mesinha, para que $\mathrm{V}$. pudesse apoiar no sofá (com o banquinho apoiando os pés), já que ele realiza suas refeiçốes ali, pois não há mesa na cozinha. A mãe foi bastante receptiva com as sugestóes e demonstrou entender a importância dessas pequenas mudanças para a prevenção da piora de $\mathrm{V}$.

Após um ano, apesar da continuidade do tratamento, em função da progressividade da doença, o quadro clínico apresentava as seguintes características: dificuldade para subir, descer e caminhar sobre uma superfície estreita; impossibilidade de alcançar objetos no chão e dificuldade de alcançar objetos na altura do joelho; a marcha ainda estava presente, entretanto, já apresentava dificuldades, demonstrando cansaço frequente.

Precisou mudar de escola, pois na qual estudava havia escadas, o que impossibilitava sua permanência na mesma. Os déficits de aprendizagem se manifestavam por meio da leitura pouco fluente e da dificuldade de compreensão da leitura, e de reconhecer quantidade numérica. Nessa etapa, foram utilizadas diversas atividades, dentre as quais se destacam:

- Confecção do jogo do banco: o objetivo foi trabalhar a área de desempenho de jogos e brincadeiras. V. esteve bastante motivado durante toda a atividade e participou bastante, escolhendo as cores do tabuleiro e as canetinhas que iria usar para escrever. V. fez o tabuleiro 
com 12 casas, sendo que três destas eram semelhantes ao jogo comercial utilizado em sessōes anteriores e as outras foram criadas por ele (comprar um carro, dia do pagamento, viagem à praia, visitas ao clube e ao parque de diversóes, etc.). Componentes de desempenho trabalhados: integração cognitiva de orientação, reconhecimento, atenção e memória, e o componente motor de coordenação motora fina e destreza. V. Apresentou menos dificuldades na leitura e na escrita, porém manteve dificuldade com operaçôes matemáticas, como reconhecer e diferenciar as centenas, somar números, mesmo referente a números baixos, como a operação " $1+1$ ". Ao final da confecçáo do tabuleiro, o jogo foi experimentado juntamente com as acadêmicas e levado para casa, para que fosse utilizado com seus familiares;

- Faz-de-conta - meio de transporte: em função do avanço do quadro motor, V. começava a apresentar limitaçōes da marcha e, portanto, se fazia necessário o seu preparo para a utilização da cadeira de rodas. Assim, foi proposta uma brincadeira de faz-de-conta na qual a cadeira de rodas se apresenta como um meio de transporte (lancha e um submarino). Componentes de desempenho trabalhados: ADM de ombro, força e trocas de posturas. V. se mostrou bastante motivado escolhendo os nomes dos personagens, sendo que ele seria o Capitáo Estrela e as acadêmicas seriam a Mulher Fogo e a Mulher Gelo; foi demonstrado que através da cadeira de rodas (lancha e submarino), ele poderia se deslocar mais rapidamente; foi-lhe ensinado a maneira de movimentar a cadeira, rodando para frente, para trás, para rodar, etc., tudo por meio do faz-de-conta com os heróis e as vilãs. V. estava muito motivado, realizando diversas trocas de posturas (sair da cadeira para a cama e vice-versa). Posteriormente, foi inserida uma caça ao tesouro, com pistas espalhadas em diversos locais do ambulatório, propiciando a ampliação de seus espaços e da relação entre V., a cadeira de rodas e outras pessoas. Ao final, V. verbalizou o prazer em realizar essa atividade.

\section{Discussão}

Como ocorre no processo natural da doença progressiva (MELO; VALDÉS; PINTO, 2005), foi observado que algumas dificuldades, como caminhar, levantar e manter o posicionamento adequado dos pés, se intensificaram.

Nos primeiros atendimentos, $\mathrm{V}$. apresentou um comportamento mais reservado e aos poucos foi estabelecendo uma relação de confiança. Mostrou-se resistente a novas atividades, principalmente as que exigiam mais habilidade motora e/ou cognitiva, dando preferência a brinquedos e brincadeiras inadequados à sua idade; contudo, com o tempo, passou a ter uma postura mais ativa e interesse por atividades mais apropriadas.

No decorrer dos atendimentos, V. trouxe algumas questóes referentes às diferenças entre as pessoas, dizendo que algumas faziam as coisas mais vagarosamente do que outras, demonstrando um pouco sua percepçáo (ainda que indiretamente) em relação às perdas que estava enfrentando.

A família foi identificada como fundamental no processo terapêutico ocupacional, sendo estimulada a desenvolver um papel bastante ativo no tratamento, principalmente no ambiente domiciliar. Gonçalves et al. (2008) destacam que a falta de apoio da família, somado a uma pobre estrutura e coesão familiar, podem influenciar no mau ajustamento psicológico da criança; entretanto, um apoio familiar efetivo pode contribuir náo somente com os aspectos emocionais como também com o aspecto físico, realizando as possíveis adaptaçóes e orientaçóes em casa, atentando sempre para o bem-estar atual e futuro da criança.

O brincar se ajustou, a participaçáo social foi estimulada e a mãe referiu procurar, na medida do possível, deixar que V. realizasse as AVDs independentemente, tendo aderido às orientaçóes dadas em atendimento domiciliar.

Em qualquer intervenção terapêutica, os objetivos vão sendo modificados ao longo do processo e, no caso de doenças progressivas, isso não difere, pois se fazem necessários maiores suportes para que a independência seja mantida. No caso apresentado, a premente perda da marcha levou à necessidade da inserção de um novo elemento na terapia, a cadeira de rodas, não como um limitante, mas como um facilitador para manutenção da qualidade de vida desse sujeito.

Tal experiência demonstra a importância da intervenção do profissional de Terapia Ocupacional junto a pacientes portadores de Distrofia Muscular, direcionada para o desenvolvimento de habilidades e de um desempenho ocupacional saudável.

\section{Agradecimentos}

À Profa. Daniela Baleroni Rodrigues Silva, a Larissa Orlandi Queiroz e a Mariana Ribeiro Marques, pelo acompanhamento do caso clínico. 


\section{Referências}

ARAÚJO, A. P. Q. C. et al. Diagnosis delay of Duchenne Muscular Dystrophy. Revista Brasileira de Saúde Materno Infantil, v. 4, n. 2, p. 179-183, 2004. http://dx.doi. org/10.1590/S1519-38292004000200008

CAROMANO, F. A. Características do Portador de Distrofia Muscular de Duchenne (DMD) - Revisão. Arquivos de Ciências da Saúde da UNIPAR, v. 3, n. 3, p. 211-218, 1999.

FONSECA, J. G.; MACHADO, M. J. F.; FERRAZ, C. L. M. S. Distrofia Muscular de Duchenne: complicaçôes respiratórias e seu tratamento. Revista de Ciências Médicas, v. 16, n. 2, p. 109-120, 2007.

GONÇALVES, M. et al. Qualidade de vida: análise comparativa entre crianças com distrofia muscular de
Duchenne e seus cuidadores. Revista Neurociências, v. 16, n. 4, p. 275-279, 2008.

HASSUI, M. K. Doenças neuromusculares. In: TEIXEIRA, E. et al. Terapia Ocupacional na Reabilitação Física. São Paulo: Roca, 2003. p. 407-428.

MELO, E. L. A.; VALDÉS, M. T. M.; PINTO, J. M. S. Qualidade de vida de crianças e adolescentes com Distrofia Muscular de Duchenne. Pediatria, v. 27, n. 1, p. 28-37, 2005. SILVA, J. D. M.; COSTA, K. S.; CRUZ, M. C. Distrofia Muscular de Duchenne: um enfoque cinesioterapêutico. Lato \& Sensu, v. 4, n. 1, p. 3-5, 2003.

ZANOTELI, E.; BETETA, J. T. Doenças neuromusculares. In: TEIXEIRA, E. et al. Terapia Ocupacional na Reabilitação Física. Sáo Paulo: Roca, 2003. p. 29-40.

\section{Contribuição dos Autores}

Tábita Enila Campos Rocha Raboni: participou da organização de fontes e/ou análises (acompanhamento do caso clínico), redação do texto. Milena Fazzio Marino da Silva: participou da organização de fontes e das análises (supervisora da intervenção junto ao caso clínico). Luzia Iara Pfeifer: Orientadora do trabalho, concepção do texto manuscrito, organização de fontes e/ou análises, redação do texto, revisão. 